\title{
Amethocaine or ketorolac eyedrops provide inade- quate analgesia in pediatric strabismus surgery
}

\author{
[L'administration d'améthocaïne ou de kétorolac par voie oculaire produit une \\ analgésie inadéquate en chirurgie de strabisme pédiatrique]
}

Jarmila Kim MD FRCPC, ${ }^{*}$ Lawrence Azavedo MD FRCA, ${ }^{*}$ Sanjay Bhananker MD FRCA, ${ }^{*}$ Gary Bonn MD FrCSC, $\dagger$ William Splinter MD FRCPC*

Purpose: Corrective strabismus surgery is associated with moderate pain after surgery. Postoperative analgesia for these patients may include topical local anesthetic agents and topical non-steroidal antiinflammatory drugs. In this prospective randomized, double-blind placebo controlled clinical trial we compared the effect of placebo to intraoperative $0.5 \%$ topical amethocaine or $0.5 \%$ topical ketorolac on pain control after strabismus surgery in children.

Methods: Following Institutional Ethics Committee approval and parental consent, we prospectively studied 51 healthy children between the ages of two and seven years who were undergoing elective bilateral recession surgery in a randomized, double-blind controlled clinical trial. Children were randomized to receive either placebo (normal saline), $0.5 \%$ amethocaine or $0.5 \%$ ketorolac eye drops at the start and end of strabismus repair surgery. Pain was assessed with a modified Children's Hospital of Eastern Ontario Pain Score in the recovery room. If the pain score was greater than 6 , the patient was administered a single oral dose of acetaminophen $\left(20 \mathrm{mg} \cdot \mathrm{kg}^{-1}\right)$.

Results: The groups had similar demographic data. Duration of surgery and anesthesia, time spent in recovery room and length of hospital stay between the three groups were similar. Pain scores and analgesic requirements while in the hospital were also similar between the groups as was the time to first analgesic administration. There were no side effects observed in any of the three treatment arms.

Conclusion: We conclude that there is no improvement in postoperative pain control after the intraoperative administration of topical $0.5 \%$ ketorolac or $0.5 \%$ amethocaine when compared to placebo in children undergoing strabismus surgery.
Objectif : La correction chirurgicale du strabisme est associée à des douleurs postopératoires modérées. L'analgésie postopératoire peut comprendre un anesthésique topique local et des anti-inflammatoires non stéroïdiens topiques. Dans cet essai clinique prospectif, randomisé, à double insu contre placebo, nous avons comparé l'effet du placebo à celui de l'administration peropératoire d'améthocaine topique à 0,5\% ou de kétorolac topique à 0,5\% sur le soulagement de la douleur après la correction chirurgicale du strabisme chez des enfants.

Méthode : Ayant reçu l'approbation du Comité d'éthique de l'institution et le consentement parental, nous avons réalisé une étude clinique prospective, randomisée, contrôlée et à double insu auprès de 5 I enfants en bonne santé, âgés de deux à sept ans, opérés pour une correction bilatérale réglée. Les enfants ont reçu, au hasard, soit un placebo (solution physiologique), soit de l'améthocaïne à 0,5 \% ou du kétorolac à 0,5\% en gouttes oculaires au début et à la fin de la correction chirurgicale du strabisme. La douleur a été évaluée en salle de réveil avec une échelle de douleur modifiée de l'Hôpital pour enfants de l'est de l'Ontario. Un score plus élevé que 6 amenait l'administration d'une dose orale unique d'acétaminophène $\left(20 \mathrm{mg} \cdot \mathrm{kg}^{-1}\right)$.

Résultats : Tous les groupes présentaient des données démographiques similaires. La durée de l'opération et de l'anesthésie, le temps passé à la salle de réveil et la longueur du séjour hospitalier ont été comparables entre les groupes. Pendant le séjour hospitalier, les scores de douleur et les besoins analgésiques ont été similaires entre les groupes, de même que le temps précédant la première administration d'analgésique. Aucun effet secondaire n'a été observé, quel que soit le traitement administré.

Conclusion : Il n'y a pas d'amélioration de l'analgésie postopératoire après l'administration peropératoire de kétorolac à $0,5 \%$ ou d'améthocaïne à 0,5\%, comparés à un placebo, chez des enfants opérés pour la correction d'un strabisme.

From the Department of Anesthesiology, ${ }^{*}$ and Ophthalmology, $†$ Children's Hospital of Eastern Ontario, University of Ottawa, Ottawa, Ontario, Canada.

Address correspondence to: Dr. Jarmila Kim, Department of Anesthesiology, Children's Hospital of Eastern Ontario, 401 Smyth Road,

Ottawa, Ontario KlH 8Ll, Canada. Phone: 613-737-2431; Fax: 613-738-4815; E-mail: kim@cheo.on.ca

Assessed July 16, 2001.

1st revision accepted February 25, 2003.

2nd revision accepted June 11, 2003. 


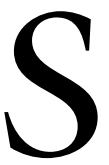

TRABISMUS surgery is among the most common eye operation in childhood and it may be associated with significant postoperative pain. ${ }^{1}$ This likely is conjunctival in origin. Opioids may decrease this pain but postoperative vomiting, which can be a major morbidity factor after strabismus surgery, may be further accentuated by their use. As little as a single dose of morphine or fentanyl significantly increases the incidence of vomiting in susceptible children. ${ }^{2}$ As both pain and protracted vomiting cause distress for children, it is important to provide safe and effective analgesia, which minimizes pain but does not induce vomiting as a side effect. Substitution of intraoperative fentanyl with placebo or ketorolac in children undergoing strabismus surgery significantly reduced postanesthesia care unit (PACU) vomiting and improved the time to discharge with no influence on the need for analgesics either early or late. ${ }^{3}$

The search for superior agents has led to the use of non-steroidal anti-inflammatory drugs (NSAIDs) for pain control after minor eye surgery, including strabismus repair. Topical diclofenac sodium has been shown to reduce prostaglandin E2 (PGE2) levels in corneas of animals undergoing laser photorefractive keratotomy. ${ }^{4}$ In surgical patients undergoing cataract surgery, diclofenac provides analgesia. ${ }^{5}$ Ketorolac has similar pharmacological effects as diclofenac.

An alternative to topical NSAIDs is local anesthetic eye drops which have been used for many years in ophthalmology to provide pain control in conscious adults and children. ${ }^{6}$ Typical procedures in which they are commonly employed are eye examinations, tonometry and minor procedures such as removal of foreign bodies. Amethocaine (tetracaine) produces rapid topical anesthesia of the conjunctiva within a few seconds after administration. One or two drops of a $0.5 \%$ solution in the eye has an effect which can last from $30 \mathrm{~min}$ to several hours. ${ }^{7}$

The aim of this study was to compare the effects of topical ketorolac to topical amethocaine and placebo on pain levels in children undergoing bilateral strabismus surgery. We hypothesized that the intraoperative use of topical amethocaine or ketorolac would have superior analgesic properties when compared to placebo. We also hypothesized that topical ketorolac would be as effective as topical amethocaine in reducing pain in children undergoing bilateral strabismus surgery.

\section{Methods}

Following Hospital Ethics Committee approval, informed consent was obtained from the parents of 51 healthy American Society of Anesthesiologists physical status I and II children between the ages of two and seven years scheduled to undergo bilateral recession correction. Children with a known allergy to NSAIDs or local anesthetics and those with a history of chronic therapeutic administration of analgesics were excluded.

A prospective three-armed double-blind randomized controlled clinical trial design was used to assess the difference between the three treatment groups. Sample size was chosen based upon data from 316 patients enrolled in previous investigations. This previous data predicted the normal time to first analgesic was $90 \pm 40$ min [mean \pm standard deviation $(S D)$ ] for a placebo group. To detect a $45-\mathrm{min}$ prolongation of analgesia, i.e., a relative increase of $45 \%$, by topical agents with a power of $80 \%$, and alpha error of $0.05 / 3$ $=0.16$, the sample size is 17 patients $/$ group if there is a $5 \%$ dropout rate.

Patients were premedicated as deemed necessary by the attending anesthesiologist with oral midazolam at a dose of $0.5 \mathrm{mg} \cdot \mathrm{kg}^{-1}$. Standard patient monitoring was used perioperatively. Induction of general anesthesia was achieved by inhalation with $\mathrm{N}_{2} \mathrm{O} / \mathrm{O}_{2}$ /halothane or by $i v$ propofol at a dose of $2.5-3.5 \mathrm{mg} \cdot \mathrm{kg}^{-1}$. A reinforced laryngeal mask airway (LMA) was inserted and general anesthesia was maintained with halothane and $\mathrm{N}_{2} \mathrm{O} / \mathrm{O}_{2}$ in a 70/30 mixture. Atropine was not administered routinely to prevent oculocardiac reflex, but was readily available.

Two drops of the study solution were placed in each eye at the start and end of surgery in a doubleblind fashion by the attending surgeon. All children were given antiemetic prophylaxis with dexamethasone $150 \mu \mathrm{g} \cdot \mathrm{kg}^{-1}$ and perphenazine $35 \mu \mathrm{g} \cdot \mathrm{kg}^{-1}$ intraoperatively. After completion of the operation, the patient was transferred to the recovery room (at varying depths of anesthesia) for continuous monitoring of vital signs and for the assessment of pain and vomiting. Minimum alveolar concentration (MAC) values of inhalational anesthesia were not recorded on departure from the operating room. The LMA was removed either asleep or awake at the discretion of the attending anesthesiologist. Pain was assessed every five minutes by the attending nurse utilizing a modified Children's Hospital of Eastern Ontario Pain Score (CHEOPS) system (Table I). If the pain score was greater than 6 , the patient was administered acetaminophen orally in a dose of $20 \mathrm{mg} \cdot \mathrm{kg}^{-1}$. If pain was deemed excessive, described as a pain score greater than 6 and unrelieved by oral acetaminophen, codeine was chosen as a second line analgesic at a dose of 1.0 $\mathrm{mg} \cdot \mathrm{kg}^{-1}$. Nausea was detected by observing the child retching or verbally admitting to nausea. Excessive vomiting (more than three times) was treated with $i$ v dimenhydrinate at a dose of $1 \mathrm{mg} \cdot \mathrm{kg}^{-1}$. The children 
TABLE I Modified Children's Hospital of Eastern Ontario Pain Scores

\begin{tabular}{lll}
\hline Item & Behaviour & Score \\
\hline Cry & No cry & 1 \\
& Moan/crying & 2 \\
Facial expression & Scream & 3 \\
& Smiling/positive & 0 \\
& Neutral & 1 \\
& Grimace & 2 \\
Verbal expression & Positive statement & 0 \\
& Non eye pain related complaint & \\
& or silence & 1 \\
\multirow{5}{*}{ Torso } & Pain complaint related to eye surgery & 2 \\
\multirow{5}{*}{ Touch } & Body at rest & 1 \\
& Moving & 2 \\
Legs & Does not touch eyes & 1 \\
& Rubs eyes persistently & 2 \\
& Relaxed or gently moving & 1 \\
& Restless/drawn up/tense/ & \\
\hline
\end{tabular}

Minimum score $=4 ;$ maximum score $=13$.

TABLE II Patient demographics

\begin{tabular}{llll}
\hline & Ketorolac & Placebo & Amethocaine \\
\hline$n$ & 14 & 18 & 19 \\
Age $(\mathrm{yr})$ & $4.7 \pm 2.6$ & $4.4 \pm 1.6$ & $4.8 \pm 1.9$ \\
Weight $(\mathrm{kg})$ & $19.3 \pm 8.4$ & $18.5 \pm 4.7$ & $18.0 \pm 3.0$ \\
Sex $(\mathrm{M}: \mathrm{F})$ & $4: 10$ & $8: 10$ & $7: 12$ \\
\hline
\end{tabular}

Note: all figures are mean \pm standard deviation.

were transferred from the postanesthesia recovery room (PARR) to the surgical day care unit (SDCU) upon achieving an Aldrete recovery room score of 10.

Normally distributed data, such as age and weight were analyzed with ANOVA, non-normally distributed data, such as pain scores were analyzed with Kruskal-Wallis rank test. Proportional data, such as sex and vomiting were analyzed with Chi square analysis. Multiple testing of data were weighted with a Bonferroni correction factor.

\section{Results}

A total of 51 children was entered into the study. After randomization there were 14 patients in the ketorolac group, 19 in the amethocaine group and 18 patients in the placebo group. Each group was comparable in terms of age, weight and sex (Table II). There was no significant difference between the three groups in terms of duration of anesthesia, time spent in the recovery room or duration of stay in the SDCU. Midazolam was given as a premedication in similar proportions to each group. More patients in the place-
TABLE III Anesthetic data

\begin{tabular}{llll}
\hline & $\begin{array}{l}\text { Ketorolac } \\
(n=14)\end{array}$ & $\begin{array}{l}\text { Placebo } \\
(n=18)\end{array}$ & $\begin{array}{l}\text { Amethocaine } \\
(n=19)\end{array}$ \\
\hline CHEOPs & $5(4-8)$ & $5(4-9)$ & $5(4-8)$ \\
Premedication (midazolam) & $8 / 14$ & $10 / 18$ & $6 / 19$ \\
Induction (iv: inhal) & $5: 9$ & $2: 16$ & $9: 10$ \\
Halothane (maint. \%) & $1.6 \pm 0.4$ & $1.4 \pm 0.4$ & $1.4 \pm 0.6$ \\
$\mathrm{~N}_{2} \mathrm{O}$ (maint. \%) & $66 \pm 5$ & $61 \pm 6$ & $68 \pm 3$ \\
iv fluids (mL) & $204 \pm 173$ & $294 \pm 186$ & $214 \pm 167$ \\
PARR fluids (mL) & $47 \pm 31$ & $60 \pm 40$ & $56 \pm 40$ \\
Anesthesia time (min) & $59 \pm 6$ & $57 \pm 13$ & $60 \pm 12$ \\
PARR time (min) & $45 \pm 16$ & $44 \pm 13$ & $45 \pm 13$ \\
SDCU time (min) & $80 \pm 19$ & $82 \pm 24$ & $80 \pm 20$ \\
\hline
\end{tabular}

CHEOP $=$ Children's Hospital of Eastern Ontario Pain Scores; $\mathrm{PARR}=$ postanesthesia recovery room; $\mathrm{SDCU}=$. surgical day care unit. Note: all figures are mean \pm standard deviation.

TABLE IV Postoperative analgesic therapy and the incidence of postoperative emesis

\begin{tabular}{llll}
\hline & $\begin{array}{l}\text { Ketorolac } \\
(n=14)\end{array}$ & $\begin{array}{l}\text { Placebo } \\
(n=18)\end{array}$ & $\begin{array}{l}\text { Amethocaine } \\
(n=19)\end{array}$ \\
\hline Emesis in PARR/SDCU & $0 / 14$ & $1 / 18$ & $0 / 19$ \\
Dimenhydrinate use in PARR & $0 / 14$ & $1 / 18$ & $0 / 19$ \\
Dimenhidrinate use in SDCU & $1 / 14$ & $2 / 18$ & $3 / 19$ \\
Acetaminophen use in PARR & $1 / 14$ & $2 / 18$ & $2 / 19$ \\
Acetaminophen use in SDCU & $5 / 14$ & $6 / 18$ & $6 / 19$ \\
$\begin{array}{l}\text { Time to first acetaminophen } \\
\text { use (min) }\end{array}$ & $57 \pm 34$ & $75 \pm 36$ & $63 \pm 40$ \\
\hline
\end{tabular}

PARR = postanesthesia recovery room; SDCU = surgical day care unit.

bo group (16/18 patients) had induction with halothane compared to the other two treatment groups (Table III).

There was no significant difference in pain scores between the three groups. The median (range) CHEOPS scores were 5 (4-9) in the ketorolac group, $5(4-7)$ in the placebo group and $5(4-8)$ in the amethocaine group (Table III). Analgesic requirements while in hospital were similar in all three groups, both in the recovery room and in the SDCU (Table IV). More children received acetaminophen in the SDCU than in the recovery room. None of the children required more than one dose of acetaminophen and none required codeine as a rescue analgesic. The average time to first administration of analgesics was similar.

In hospital, postoperative nausea and vomiting (PONV) was minimal. Overall emesis rate in SDCU was $2 \%$ (Table IV). Dimenhydrinate administration was similar (Table IV). No child required inpatient admission for persistent nausea and vomiting. No other complications were noted. 


\section{Discussion}

In our current study we could not detect a benefit of treatment with either topical ketorolac or amethocaine, when compared to placebo. A similar study performed by Bridge $e t a l$. also failed to show a difference between the analgesic properties of $0.5 \%$ ketorolac and placebo. ${ }^{8}$ Although earlier investigations suggested a beneficial effect of using topical diclofenac, a similar analgesic effect from ketorolac has not been observed. ${ }^{9}$

Traditionally, opioids have been used as a first line agent for postoperative pain control in children undergoing strabismus repair. However, PONV is a serious problem associated with this approach. Until recently we did not routinely administer prophylactic analgesics in elective strabismus surgery in children, although recent literature may suggest that prophylactic analgesia is of benefit in this population.

The induction of anesthesia in our study was achieved either by iv propofol or by inhalation with $\mathrm{N}_{2} \mathrm{O} / \mathrm{O}_{2} /$ halothane, at the discretion of the attending anesthesiologist. Although some believe that propofol has a specific antiemetic effect, there exists no physiologic data as to its effect on the chemoreceptor trigger zone or the emetic centre. When used solely as an induction drug, propofol has not been found to be beneficial in reducing the incidence of nausea or vomiting. When used in therapeutic doses throughout surgery, patients are less likely to vomit in the PACU, but are not necessarily discharged earlier or have less vomiting late in recovery. ${ }^{10-13}$ Similarly, when inhalation anesthesia is administered without narcotics and in the absence of pain the incidence of vomiting is very low $(9 \%) .{ }^{14}$

Assessment of pain in younger children is difficult because of their limited understanding and verbal abilities. In this study we used a modified CHEOPS scoring system to assess postoperative pain in these patients. We have had considerable experience with the use of this pain scale and find it a valid and reliable method of assessing pain in children. We do, however, agree with Bridge et.al. that there are difficulties with CHEOPS in this specific pain model, as it may not be a specific measure of ocular pain and therefore may not accurately reflect pain scores in this age population. ${ }^{8}$

As our goal was to avoid opioids and there is no iv preparation of NSAID other than ketorolac available in Canada, an oral preparation of acetaminophen was used as a first choice for rescue analgesia if the CHEOPS score was greater than 6 . The absorption half-life for the oral preparation is believed to be 4.5 min without a detectable lag time. ${ }^{15}$ Overall, $43 \%$ of children required acetaminophen postoperatively and this was distributed equally amongst the three groups. Acetaminophen use in PARR and in SDCU demonstrates that the incidence of postoperative pain requiring treatment is low in our population and equally distributed in all three groups. None of the children studied required a second dose of acetaminophen or codeine, the second line rescue analgesic chosen for this study. The lack of codeine use would be expected to minimize the incidence of vomiting.

Postoperative vomiting was a rare event in our study. Emesis was reported in only one child in the placebo group although, overall, seven children received dimenhydrinate postoperatively. Unfortunately, some of these children may have accidentally received dimenhydrinate in the PACU for sedation rather than nausea. The low incidence of vomiting may be attributed to the avoidance of opioids and the use of perphenazine and dexamethasone intraoperatively. ${ }^{16}$ Unfortunately PONV was only recorded during the short hospital stay. It might have been useful to obtain data for PONV and pain scores after discharge from hospital during the first $24 \mathrm{hr}$ and evaluate the incidence of late nausea and vomiting.

Bridge et al. reported the overall incidence of postoperative vomiting to be $3 \%$ in hospital and $23 \%$ in the first $24 \mathrm{hr}$ in a similar study. ${ }^{8}$ They speculated that morphine might have been a contributory emetic stimulus, administered to $43 \%$ of children after strabismus repair. In addition, their protocol did not include intraoperative antiemetic prophylaxis.

The current study's sample size was based upon historical data. This historical data had a relatively large $n$, but was markedly different then the current study's population. It was predicted that our placebo group's time to first analgesia would have a mean and SD of 90 and 40 , respectively, but it was actually 57 and 34 , respectively. The study still has a power of $80 \%$ to detect an absolute difference of $45 \mathrm{~min}$ in time to first analgesia, but the power to detect a relative difference in groups of $50 \%$, i.e., time to first analgesia of $57 \mathrm{~min} v s$ $85 \mathrm{~min}$ is only $29 \%$.

In conclusion, this study did not demonstrate a beneficial effect of topical ketorolac or amethocaine $v s$ placebo for pain control in children undergoing strabismus surgery.

\section{References}

1 Shende D, Das K. Comparative effects of intravenous ketorolac and pethidine on perioperative analgesia and postoperative nausea and vomiting (PONV) for paediatric strabismus surgery. Acta Anaesthesiol Scand 1999; 43: 265-9.

2 Weinstein MS, Nicolson SC, Schreiner MS. A single dose of morphine sulfate increases the incidence of vomiting 
after outpatient inguinal surgery in children.

Anesthesiology 1994; 81: 572-7.

3 Mendel HG, Guarnieri KM, Sundt LM, Torjman MC. The effects of ketorolac and fentanyl on postoperative vomiting and analgesic requirements in children undergoing strabismus surgery. Anesth Analg 1995; 80:

1129-33.

4 Morton NS, Benham SW, Lawson RA, McNicol LR. Diclofenac vs oxybuprocaine eyedrops for analgesia in paediatric strabismus surgery. Paediatr Anaesth 1997; 7: 221-6.

5 Fry LL. Efficacy of diclofenac sodium solution in reducing discomfort after cataract surgery. J Cataract Refract Surg 1995; 21: 187-90.

6 Carden SM, Colville DJ, Davidson AJ, et al. Adjunctive intra-operative local anaesthesia in paediatric strabismus surgery: a randomized controlled trial. Aust $\mathrm{N} \mathrm{Z} \mathrm{J}$ Ophthalmol 1998; 26: 289-97.

7 Watson DM. Topical amethocaine in strabismus surgery. Anaesthesia 1991; 46: 368-70.

8 Bridge HS, Montgomery CJ, Kennedy RA, Merrick PM. Analgesic efficacy of ketorolac $0.5 \%$ ophthalmic solution (Accular) in paediatric strabismus surgery. Paediatr Anaesth 2000; 10: 521-6.

9 Apt L, Voo I, Isenberg SJ. A randomized clinical trial of the nonsteroidal eyedrop diclofenac after strabismus surgery. Ophthalmology 1998; 105: 1448-54.

10 Hannallah RS, Britton JT, Schafer PG, Patel RI, Norden JM. Propofol anaesthesia in paediatric ambulatory patients: a comparison with thiopentone and halothane. Can J Anaesth 1994; 41: 12-8.

11 Reimer EJ, Montgomery CJ, Bevan JC, Merrick PM, Blackstock D, Popovic V. Propofol anaesthesia reduces early postoperative emesis after paediatric strabismus surgery. Can J Anaesth 1993; 40: 927-33.

12 Martin TM, Nicolson SC, Bargas MS. Propofol anesthesia reduces emesis and airway obstruction in pediatric outpatients. Anesth Analg 1993; 76: 144-8.

13 Weir PM, Munro HM, Reynolds PI, Lewis IH, Wilton NC. Propofol infusion and the incidence of emesis in pediatric outpatient strabismus surgery. Anesth Analg 1993; 76: 760-4.

14 Murray DJ, Schmid CM, Forbes RB. Anesthesia for magnetic resonace imaging in children: a low incidence of protractive post-procedure vomiting. J Clin Anesth 1995; 7: 232-6.

15 Romsing J, Ostergaard D, Senderovitz T, Drozdziewicz $D$, Sonne J, Ravn G. Pharmacokinetics of oral diclofenac and acetaminophen in children after surgery. Paediatr Anaesth 2001; 11: 205-13.

16 Splinter W, Roberts DJ. Prophylaxis for vomiting by children after tonsillectomy: dexamethasone versus perphenazine. Anesth Analg 1997; 85: 534-7. 